\title{
BMJ Open Exploration of implementation, financial and technical considerations within allied health professional (AHP) telehealth consultation guidance: a scoping review including UK AHP professional bodies' guidance
}

\author{
Enza Leone, ${ }^{1}$ Nicola Eddison, ${ }^{1,2}$ Aoife Healy (D) , ${ }^{1}$ Carolyn Royse ${ }^{3}$ \\ Nachiappan Chockalingam (iD) 1
}

To cite: Leone $\mathrm{E}$, Eddison $\mathrm{N}$, Healy $\mathrm{A}$, et al. Exploration of implementation, financial and technical considerations within allied health professional (AHP) telehealth consultation guidance: a scoping review including UK AHP professional bodies' guidance. BMJ Open 2021;11:e055823. doi:10.1136/ bmjopen-2021-055823

- Prepublication history and additional supplemental material for this paper are available online. To view these files, please visit the journal online (http://dx.doi.org/10.1136/ bmjopen-2021-055823).

EL, NE and AH are joint first authors.

Received 26 July 2021 Accepted 29 October 2021

Check for updates

(C) Author(s) (or their employer(s)) 2021. Re-use permitted under CC BY-NC. No commercial re-use. See rights and permissions. Published by BMJ.

For numbered affiliations see end of article.

Correspondence to

Dr Aoife Healy;

a.healy@staffs.ac.uk

\section{ABSTRACT}

Objectives The COVID-19 pandemic has resulted in a shift to remote consultations, but telehealth consultation guidelines are lacking or inconsistent. Therefore, a scoping review was performed to chart the information in the articles exploring telehealth for the UK allied health professionals (AHPs) and compare them with the UK AHP professional bodies' guidelines.

Design Scoping review following Aksey and 0' Malley methodological framework.

Data sources CINHAL and MEDLINE were searched from inception to March 2021 using terms related to 'telehealth', 'guidelines' and 'AHPs'. Additionally, the UK AHP professional bodies were contacted requesting their guidelines.

Study selection Articles exploring telehealth for patient consultations, written in English and published in peerreviewed journal or guidelines available from UK AHP professional bodies/their websites were considered eligible for review.

Data extraction One reviewer extracted data concerning three overarching domains: implementation, financial and technological considerations.

Results 2632 articles were identified through database searches with 21 articles eligible for review. Eight guidelines were obtained from the UK AHP professional bodies with a total of 29 included articles/guidelines. Most articles were published in the last two years; there was variety in telehealth terminology, and most were developed for occupational therapists, physiotherapists and speech and language therapists. Information was lacking about the assessment of telehealth use and effectiveness, barriers and limitations, the logistical management, the family's and caregiver's roles and the costs. There was lack of clarity on the AHPs' registration requirements, costs and coverage, and legal aspects.

Conclusion This study identified gaps in current guidelines, which showed similarities as well as discrepancies with the guidance for non-AHP healthcare professionals and revealed that the existing guidelines do not adequately support AHPs delivering telehealth

\section{STRENGTHS AND LIMITATIONS OF THIS STUDY}

$\Rightarrow$ This is the first study to provide a review of the guidelines for telehealth consultations within UK allied health professional (AHP) service provision.

$\Rightarrow$ A scoping review, following recommended guidelines and framework, was conducted with systematic literature searches to identify articles related to AHP telehealth consultation guidance and the $14 \mathrm{UK}$ AHP professional bodies were contacted, and where required, their websites were accessed to identify the telehealth consultation guidelines they provide to their members.

$\Rightarrow$ Identified articles and guidelines were assessed to ascertain the presence and detail of implementation, financial and technical considerations within them.

$\Rightarrow$ Articles potentially relevant for the purpose of this work may have been missed due to limiting the grey literature search to the UK AHP professional bodies and their websites.

$\Rightarrow$ A limitation of this study is that only articles written in English and having specific methodological designs were examined.

consultations. Future research and collaborative work across AHP groups and the world's leading health institutions are suggested to establish common guidelines that will improve AHP telehealth services.

\section{BACKGROUND}

In 2010, the WHO defined telehealth as the use of communication technologies to deliver healthcare services such as disease prevention, diagnosis and treatment, and other related activities as research and staff training. ${ }^{1}$ The original term for telehealth, coined in 1970s, was telemedicine; ${ }^{2}$ however, over the years, a variety of terms 
(eg, telemedicine, telemonitoring, videoconferencing, ehealth, mhealth and remote consultations) has been often used interchangeably with telehealth. ${ }^{2}$ Comparable or higher outcomes than face-to-face consultations, good patients' satisfaction, greater accessibility, convenience and reduced travel as well as wait times are some of the factors that have led to increased telehealth usage and acceptability. ${ }^{3}$

Although telehealth can be considered an efficient and safe modality to deliver healthcare through stateof-art communication technologies, in practice, there are barriers that can lead to unintended consequences; these include technological constraints such as inadequate internet bandwidth, lack of skills among users, inconsistent reimbursement regulations, and patient confidentiality, privacy as well as data security issues. ${ }^{3}$ Alone or in combination, technology failures and clinical negligence, omission and miscommunication as well as misdiagnosis can cause emotional, spiritual, social or material harm to patients. For example, in 2020, video consultation recordings and other confidential information of UK patients using a telehealth start-up were made accessible to any start-up user due to a software error. ${ }^{4}$ Additionally, concerns have been raised about the risk of patient harm resulting from the lack of diagnostic and therapeutic quality of services delivered through telehealth, as this can lead to highly infectious and life-threatening conditions being missed. ${ }^{5}$ This can result in substantial risk of death to people with untreated conditions resulting in clinical complications and pose a high risk of communitybased disease transmission and potential loss of life. ${ }^{5}$ The contactless nature of telehealth consultations and the possible lack of continuity of care are the other factors that may contribute to clinicians not having a full understanding of the patient's past medical and family history, leading inevitably to a less effective care and to patient suffering. These barriers, together with their ethical and legal implications, need to be considered when implementing telehealth consultations within a service. Robust guidelines should be available to assist clinicians in mitigating these barriers by offering clear instructions on how to provide remote consultations, which would also help them limit inappropriate and ineffective interventions, and most importantly, harm to patients. ${ }^{6}$

The COVID-19 pandemic led to a rapid transition to remote consultations as a stand-alone treatment modality to minimise the risk of COVID-19 transmission, while ensuring continuity of care for patients and preserving healthcare resources. ${ }^{7}$ This radical change resulted in an unprecedented expansion of telehealth and led stakeholders to rethink care delivery models. ${ }^{8}$ Although the pandemic may represent a definitive transition from traditional to technology-mediated care, concerns and limitations related to telehealth and the unintended risks, errors and harm that can occur to patients during and/or as a result of remote consultations are still present. The information regarding legal policies, guidelines to support clinicians while providing care remotely and the minimum standards for using telehealth is lacking or inconsistent across countries. ${ }^{1}$ Furthermore, the introduction of new technologies within existing work routines and conventional practices can be disruptive at both service and clinician level, ${ }^{9}$ making healthcare professionals more vulnerable to malpractice. To ensure successful integration of telehealth into existing healthcare systems, there is a need to develop new or revise existing clinical practice guidelines for telehealth, which may act as 'trailblazers', ${ }^{9}$ regulating and guiding novel technologies and practices, thereby preventing the performance of harmful interventions, preserving patients' safety and promoting high-quality of care.

Ninety-seven per cent of the respondents to a survey by the American Telemedicine Association believe that telehealth should have guidelines, which would standardise approaches and, consequently, improve telehealth credibility to patients and clinicians and limit its liability. ${ }^{10}$ Additionally, guidelines are necessary to inform clinicians on how to set up remote consultations considering defined implementation and technological requirements and patients' as well as their family's needs thereby providing safe and effective care ${ }^{10}$ Furthermore, identifying and defining telehealth standards would help insurance companies, regulators and policymakers develop and/or adapt evidence-based policies and guidelines, which can be used to set out the standard of care in legal cases and to guide telehealth use in AHP services.

This scoping review, based on a systematic search of the literature, with a comparison of the telehealth guidance published in journals with those developed by UK AHP professional bodies, aims to summarise the information detailed in telehealth guidelines for allied health professionals (AHPs). It will map the current UK and international evidence on telehealth for AHP patient consultations, establish the existing research needs and serve as the basis for influencing clinical practice and for developing guidelines and policies. For this study, we will use the term telehealth to refer to the use of telecommunication technologies to conduct remote patient consultations. The objectives of this study are to: (1) explore the AHP telehealth guidelines currently available in the scientific literature and compare them with those developed by the UK AHP professional bodies and to (2) identify the considerations necessary to set up and deliver AHP patient consultations via telehealth.

\section{METHODS}

\section{Protocol design}

This scoping review followed the methodology proposed by Levac et al, ${ }^{11}$ which builds on the methodological framework developed by Aksey and O' Malley. ${ }^{12}$ The Preferred Reporting Items for Systematic Reviews and Meta-Analyses guidelines extension for scoping reviews were also used throughout the review process. ${ }^{13}$ The review protocol for this review was not registered. 
Stage 1: identifying the research question

The research questions that guided this scoping review were:

- How do the UK AHP professional bodies telehealth guidelines compare with each other and to the available literature on AHP telehealth consultation guidance?

- What are the implementation, financial and technical considerations necessary to set up and deliver AHP patient consultations via telehealth?

\section{Stage 2: identifying relevant studies: search strategy}

A combination of database and grey literature searching was used for this study. The paper includes both: (1) articles identified via databases, hereafter referred to as articles and (2) guidelines identified from UK AHP professional bodies or their websites, hereafter referred to as guidelines. The search of the grey literature was limited to the guidelines provided by the UK AHP professional bodies or available on their websites, which were developed either by the UK professional bodies or the National Health Service (NHS).

\section{Articles identified via databases}

A systematic literature search was conducted using MEDLINE and CINAHL via EBSCOhost. These databases were searched from their inception to March 2021 with a series of subject headings and free-text terms for the following keywords: 'telehealth', 'Allied Health Professional' and 'guidelines'. The set of keywords for 'Allied Health Professional' included terms referring only to the UK NHS's 14 AHP professionals: ${ }^{14}$ art therapists, drama therapists, music therapists, chiropodists/podiatrists, dietitians, occupational therapists, operating department practitioners, orthoptists, osteopaths, paramedics, physiotherapists, prosthetists and orthotists, radiographers, and speech and language therapists. Keywords were combined with Boolean operators; the full search strategy is available in online supplemental file 1.

\section{Guidelines identified from UK AHP professional bodies or their websites}

All 14 UK AHP professional bodies were contacted to request the telehealth consultations guidelines they provide to their members. In case of no response or absence of existing guidelines, the AHP professional bodies' websites were accessed to search for other possible available resources.

\section{Stage 3: selection of relevant articles}

All the records identified through database searching were exported into citation management software (Mendeley, Elsevier B.V.), where all duplicates were automatically removed. To supplement this, one reviewer (EL) also undertook a manual check of the identified articles to identify duplicates. One reviewer (EL) independently screened the records (titles and abstracts) to assess their eligibility based on the inclusion and exclusion criteria. Subsequently, one reviewer (EL) screened the full text of articles and relevant articles were selected for data retrieval. Any uncertainty about eligibility was resolved through a discussion with the second reviewer (AH). In case of disagreement on eligibility between the two reviewers, then the article was discussed with the wider team.

\section{Inclusion and exclusion criteria}

The following inclusion and exclusion criteria guided the selection of both: (1) articles identified via databases and (2) guidelines identified from UK AHP professional bodies or their websites.

\section{Articles identified via databases: inclusion and exclusion criteria Inclusion}

- Articles exploring the use of telehealth for patient consultations in the 14 NHS AHPs recognised in the UK or in healthcare professions in which UK NHS AHPs were included.

- Guidelines, practical guidance, consensus statements, editorials, experts' opinions, case studies, editorial and narrative as well as systematic reviews from peerreviewed journals were considered eligible for review.

- Articles whose full text was accessible.

- Articles available in English language.

\section{Exclusion}

- Articles exploring the use of telehealth for purposes other than patient consultations or not requiring direct interaction between patients and AHP professionals (eg, remote monitoring, training, health apps, etc).

- Articles where telehealth was used by AHP students.

- Letters to the editor, patient education handouts and reviews not providing clear guidance on how to use telehealth for patient consultations.

- Articles published in non-peer reviewed journals such as magazines.

- Articles whose full text was not accessible.

- Articles in languages other than English.

Guidelines identified from UK AHP professional bodies or their websites: inclusion and exclusion criteria

\section{Inclusion}

- Telehealth guidelines received directly from the UK AHP professional bodies.

- Telehealth-related information present in the UK AHP professional bodies' websites that were produced directly by them or by the NHS.

\section{Exclusion}

- Resources available on the AHP professional bodies' websites that were produced by third parties.

\section{Stage 4: charting the data}

Data were extracted from the abstracts and the full texts of the included articles by one reviewer (EL). Any uncertainties were eliminated by discussion with a second reviewer $(\mathrm{AH})$ and with the wider team, if any 
Table 1 Implementation, financial and technical considerations extracted from articles identified through the database search and UK allied health professionals bodies' guidelines

\begin{tabular}{|c|c|c|}
\hline Implementation considerations & Financial considerations & Technical considerations \\
\hline
\end{tabular}

disagreement between the two reviewers was not resolved. The reviewer followed a data charting form, collectively developed by the research team, which included telehealth domains reported in guidelines produced by the NSW Agency for Clinical Innovation such as implementation, financial and technical considerations. ${ }^{15}$ The implementation considerations included key factors for the successful telehealth delivery such as the identification of the purposes for which telehealth can be used, patient's and clinician's eligibility criteria and the assessment strategies to adopt to monitor telehealth use and effectiveness. While the financial considerations covered the costs, reimbursement and coverage aspects of telehealth, the technological considerations summarised the technological requirements and the facility spaces necessary for telehealth as well as the legal, privacy and security issues concerning remote consultations via telehealth. During the piloting phase of the charting form, we also identified other relevant telehealth domains that were added to the final data extraction form such as the purpose telehealth can be used for, patient eligibility, AHPs' eligibility, team characteristics, limitations and barriers, and family's as well as caregiver's roles. Data were analysed through a descriptive analytical approach that involved the reviewer conducting an in-depth evaluation of the included studies to identify in each article/guideline any of the domains summarised in table 1 . The depth of discussion of the different domains within the articles was not assessed.

For each article, the following additional information was extracted: country of publication, study design, clinical population, audience, telehealth terminology, type of telehealth used and any relationship with the COVID-19 pandemic. The same extraction criteria were applied to the guidelines received from the UK AHP professional bodies and to the resources available on AHP professional bodies' websites.

Due to the design of the current study, a quality assessment of the included papers was not conducted. We used the level of evidence grading scale developed by Wright $e t$ $a l^{16}$ for methodological appraisal of all the articles identified via the database searches. The included articles were appraised using a 1-5 grading scale, with higher scores indicating lower methodological quality.

\section{Stage 5: collating, summarising and reporting of results}

A narrative report was produced to summarise the implementation, financial and technical considerations of the currently available telehealth article/guidelines and to highlight any gaps in the existing guidance. Any similarities or differences between/within international and UK articles/guidelines were also reported.

\section{Stage 6: consultation}

This stage was not incorporated in the design of our study.

\section{Patient and public involvement}

No patient involved.

\section{RESULTS}

The database searches identified 2632 articles (Medline: n=1753; CINHAL: $n=879$ ). After duplicates were removed, either automatically or manually, this was reduced to 2034. Following title/abstract review, 24 articles progressed to full-text review. Of these, three were excluded as they did not provide information relevant to this study. Therefore, 21 articles were deemed eligible for review. Of the 14 UK AHP professional bodies, seven responded to our request for information (chiropodists/podiatrists, orthoptists, osteopaths, paramedics, prosthetics and orthotics, radiographers, and speech and language therapists). Five had produced telehealth guidelines that they provided (chiropodists/podiatrists, orthoptists, osteopaths, prosthetics and orthotics and speech and language therapists), either via email or via a web page link directing to their website, for review. Of those professional bodies who did not respond, three (dietitians, occupational therapists and physiotherapists) had information that we 


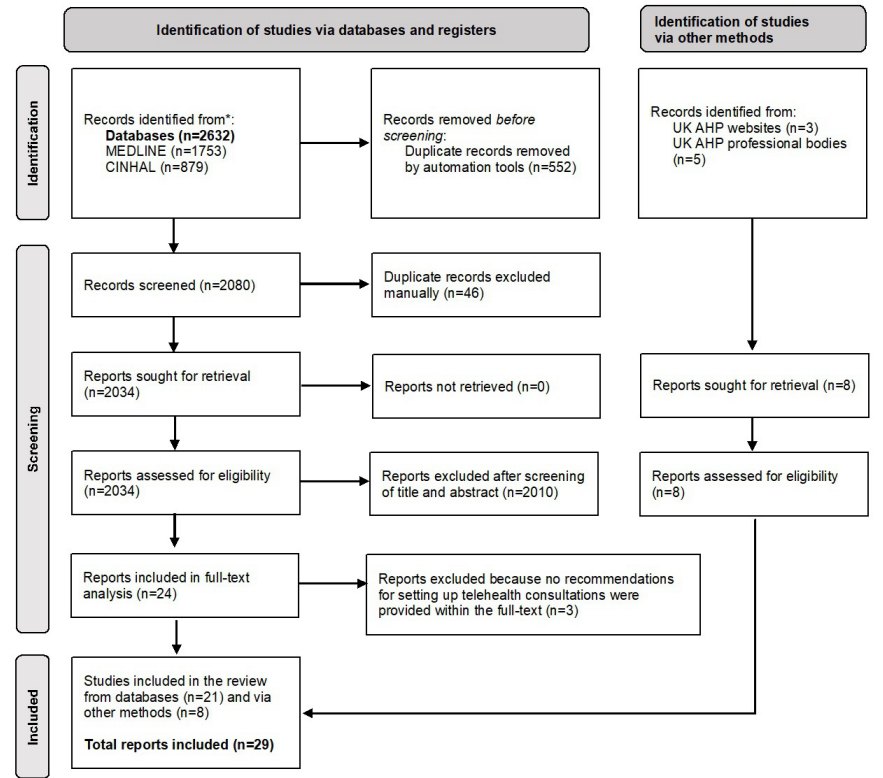

Figure 1 Flow diagram of the study selection process. AHP, allied health professional.

were able to access via their websites. Therefore, a total of eight guidelines obtained from the UK AHP professional bodies were included in the review. Adding this to the 21 articles identified through the database search, a total of 29 articles/guidelines were included for synthesis. Figure 1 summarises the study selection process. Information on the general characteristics of the included articles is provided in tables 2 and 3 .

\section{Characteristics of included articles/guidelines}

Of the 21 included articles identified through the database searches, the majority was published in the USA $(n=9)$, followed by Canada $(n=4)$ and Australia $(n=3)$. Three were not country specific as they were developed by international boards and the two remaining articles were from Finland and Saudi Arabia. When articles/guidelines were categorised by year of publication (figure 2), it was evident that telehealth is a recent and growing area of research with all articles being published within the last two decades and more than half of them $(n=16)$ being developed in the last twoyears. Notably, 13 (45\%) of the included articles/ guidelines were published in response to the COVID-19 pandemic; all the guidelines identified through the UK AHP professional bodies or their websites and five of the articles identified through the database searches were produced in response to the COVID-19 pandemic.

For the articles identified through the database searches, there were five position statements, four clinical practice guidelines and three single expert's opinions. Other study designs were consensus statement, group expert opinion, case study, literature review and editorial. This reflected on the level of evidence with 19 articles categorised as level 5 evidence. Most of the articles/guidelines were developed for occupational therapists, physiotherapists and speech and language therapists $(n=7$ for each AHP group, including one for each profession from the UK AHP professional bodies). Three articles/guidelines were designed for all AHPs, two for dietitians (one from the UK AHP professional bodies) and one guideline was published for each of the following AHP groups, all from the UK AHP professional bodies: art therapist, orthoptists, osteopaths, prosthetists and orthotists and chiropodists/podiatrists.

Twenty articles/guidelines were not disease or population specific, while six provided information for managing people with specific conditions such as Duchenne muscular dystrophy, head and neck cancer, voice and upper airways dysfunctions, overweight/ obesity and malnutrition disorders, and spinal disorders. Three offered suggestions for specific populations such as women with breast cancer, adults with functional impairment and older adults as well as disabled people. A combination of audio and video telehealth consultation modalities were discussed in 16 articles/guidelines, while video technologies were discussed alone in five articles/guidelines. Three articles/guidelines adopted video technologies either alone or in combination with audio modalities for group patient sessions. A wide variety of terminology referring to telehealth has been used across articles/guidelines with telehealth, telemedicine, telecommunication, telerehabilitation and telepractice the most frequently used terms (see figure 3).

\section{Implementation, financial and technical considerations}

The domains contained in the telehealth articles/guidelines are summarised in table 4 . The table includes the percentages of the articles/guidelines that discussed the domains and of the domains included in each article/ guideline to provide an indication of the completeness of the articles/guidelines. Among the topics, the purpose telehealth can be used for, the patient eligibility, AHP's and patient's training and privacy as well as security issues were the most reported aspects, in both the articles identified through the databases and in the UK AHP professional body guidelines. The legislation, legal and ethical aspects were other considerations frequently reported among articles identified through database searches, while patient information and room, session and technical requirements were popular among the UK AHP professional body guidelines. In both groups, the less explored aspects were the assessment of telehealth use and effectiveness, the barriers and limitations, the logistical management, the family's and/or caregiver's roles and the financial considerations expressed in terms of costs, reimbursement and coverage. No implementation and technical considerations were provided by Hailey et $a l^{17}$ and the British Association of Prosthetists and Orthotists (BAPO), ${ }^{18}$ respectively. The most comprehensive guideline among those from the UK AHP professional bodies was produced by the Royal College of Speech and Language Therapists (RCSLT) ${ }^{19}$ A summary of the main findings is provided below with additional information provided in online supplemental file 2. 
Table 2 Characteristics of the included articles identified via database searches

\begin{tabular}{|c|c|c|c|c|c|c|c|c|c|}
\hline ID & Authors & Year & $\begin{array}{l}\text { Country of } \\
\text { publication }\end{array}$ & Type of article & $\begin{array}{l}\text { Level of } \\
\text { evidence }\end{array}$ & Audience & $\begin{array}{l}\text { Clinical } \\
\text { population }\end{array}$ & $\begin{array}{l}\text { Type of } \\
\text { telehealth used }\end{array}$ & $\begin{array}{l}\text { COVID-19 } \\
\text { pandemic related }\end{array}$ \\
\hline 1 & Bamaga et $a l^{34}$ & 2021 & Saudi Arabia & $\begin{array}{l}\text { Consensus } \\
\text { statement }\end{array}$ & V & $\begin{array}{l}\text { AHPs and } \\
\text { caregivers }\end{array}$ & DMD & Not specified & Yes \\
\hline 2 & Ben-Aharon $^{20}$ & 2019 & USA & Practical guideline & V & SLTs & Not specified & $\begin{array}{l}\text { Video } \\
\text { consultations }\end{array}$ & No \\
\hline 3 & Bierman et $a l^{24}$ & 2018 & USA & Literature review & V & OTs and PTs & Not specified & $\begin{array}{l}\text { Audio and video } \\
\text { consultations }\end{array}$ & No \\
\hline 4 & Burns and Wall ${ }^{31}$ & 2017 & Australia & Literature review & V & SLTs & $\begin{array}{l}\text { People with head } \\
\text { and neck cancer }\end{array}$ & $\begin{array}{l}\text { Video } \\
\text { consultations }\end{array}$ & No \\
\hline 5 & Cason $^{44}$ & 2014 & USA & Expert opinion & V & OTs and PTs & Not specified & Not specified & No \\
\hline 6 & Collie et $a l^{40}$ & 2006 & Canada & $\begin{array}{l}\text { Clinical practice } \\
\text { guideline }\end{array}$ & V & Art therapists & $\begin{array}{l}\text { Women with breast } \\
\text { cancer }\end{array}$ & $\begin{array}{l}\text { Audio and video } \\
\text { consultations - } \\
\text { group sessions }\end{array}$ & No \\
\hline 7 & Denton $^{25}$ & 2003 & USA & Expert opinion & V & SLTs & Not specified & Not specified & No \\
\hline 8 & Doll et $a l^{45}$ & 2021 & USA & $\begin{array}{l}\text { Clinical practice } \\
\text { guideline }\end{array}$ & V & SLTs & $\begin{array}{l}\text { People with voice } \\
\text { and upper airways } \\
\text { dysfunctions }\end{array}$ & $\begin{array}{l}\text { Audio and video } \\
\text { consultations }\end{array}$ & No \\
\hline 9 & Hailey et $a l^{17}$ & 2005 & Canada & Experts' opinion & V & AHPs & Not specified & $\begin{array}{l}\text { Video } \\
\text { consultations }\end{array}$ & No \\
\hline 10 & Haldeman et $a l^{21}$ & 2021 & International & $\begin{array}{l}\text { Consensus } \\
\text { statement }\end{array}$ & V & $\begin{array}{l}\text { A series of } \\
\text { healthcare } \\
\text { professionals } \\
\text { including PTs } \\
\text { and patients }\end{array}$ & $\begin{array}{l}\text { People with spinal } \\
\text { disorders }\end{array}$ & $\begin{array}{l}\text { Audio and video } \\
\text { consultations }\end{array}$ & Yes \\
\hline 11 & Jacobs et $a l^{41}$ & 2015 & International & Position statement & V & OTs & Not specified & Not specified & No \\
\hline 12 & Kelly et $a l^{30}$ & 2020 & Australia & Position statement & V & Dietitians & $\begin{array}{l}\text { People with } \\
\text { chronic disease } \\
\text { related to } \\
\text { overweight/obesity } \\
\text { and malnutrition }\end{array}$ & $\begin{array}{l}\text { Audio and video } \\
\text { consultations }\end{array}$ & No \\
\hline 13 & Lee et $a l^{28}$ & 2020 & USA & Expert opinion & V & PTs & Not specified & $\begin{array}{l}\text { Audio and video } \\
\text { consultations }\end{array}$ & Yes \\
\hline 14 & Meredith et $a l^{39}$ & 2013 & Australia & Experts' opinion & V & SLTs & Not specified & $\begin{array}{l}\text { Video } \\
\text { consultations }\end{array}$ & No \\
\hline 15 & Middleton et $a /^{35}$ & 2020 & USA & Case study & IV & PTs & $\begin{array}{l}\text { Adults with } \\
\text { functional } \\
\text { impairment }\end{array}$ & $\begin{array}{l}\text { Audio and video } \\
\text { consultations }\end{array}$ & Yes \\
\hline 16 & Quigley et $a l^{29}$ & 2020 & Canada & Editorial & V & PTs & Not specified & Not specified & Yes \\
\hline 17 & Simila et $a l^{42}$ & 2014 & Finland & Case study & IV & OTs & $\begin{array}{l}\text { Older adults and } \\
\text { disabled people }\end{array}$ & $\begin{array}{l}\text { Video } \\
\text { consultations - } \\
\text { group sessions }\end{array}$ & No \\
\hline 18 & $\begin{array}{l}\text { Waguespack et } \\
\text { al }{ }^{43}\end{array}$ & 2005 & USA & Position statement & V & SLTS & Not specified & $\begin{array}{l}\text { Audio and video } \\
\text { consultations }\end{array}$ & No \\
\hline 19 & Wakeford et $a l^{27}$ & 2005 & USA & Position statement & V & $\begin{array}{l}\text { OTs+OT } \\
\text { assistants }\end{array}$ & Not specific & $\begin{array}{l}\text { Audio and video } \\
\text { consultations }\end{array}$ & No \\
\hline 20 & Wong et $a l^{32}$ & 2021 & Canada & $\begin{array}{l}\text { Clinical practice } \\
\text { guideline }\end{array}$ & V & $\begin{array}{l}\text { Healthcare } \\
\text { professionals }\end{array}$ & Not specified & $\begin{array}{l}\text { Audio and video } \\
\text { consultations }\end{array}$ & No \\
\hline 21 & $\begin{array}{l}\text { World Federation } \\
\text { of Occupational } \\
\text { Therapists }^{26}\end{array}$ & 2014 & International & Position statement & V & OTs & Not specified & Not specified & No \\
\hline
\end{tabular}

AHPs, allied health professionals; DMD, Duchenne muscular dystrophy; OTs, occupational therapists; PTs, physiotherapists; SLTs, speech and language therapists.

\section{Implementation considerations}

\section{Purpose telehealth can be used for}

Eighteen articles/guidelines (59\% of all the articles/ guidelines), including most of the UK AHP professional bodies' guidelines $(n=7)$, stated the purpose of the guidance. They indicated that telehealth can be used for a variety of services including triage,${ }^{20-23}$ advice provision, ${ }^{21} 2224$ assessment, ${ }^{18} 192225$ intervention, ${ }^{25-27}$ provision of piece of equipment, ${ }^{18}$ remote monitoring, ${ }^{23} 242627$ service evaluation, ${ }^{22}$ patient education, ${ }^{21}{ }^{24} 27$ consultations with other AHPs ${ }^{22} 26$ and staff supervision. ${ }^{24} 27$

\section{Patient eligibility}

Most telehealth articles/guidelines (69\% $(\mathrm{n}=20)$ of all included articles/guidelines, six from the UK AHP professional bodies) contained elements related to patient eligibility. Four of the articles/guidelines ${ }^{20} 28-30$ stated that patients should be triaged prior to telehealth 
Table 3 Characteristics of the included guidelines identified through UK AHP professional bodies or their websites

\begin{tabular}{|c|c|c|c|c|c|c|c|}
\hline ID & AHPs & Authors & Year & Source & Clinical population & Type of telehealth used & $\begin{array}{l}\text { COVID-19 pandemic } \\
\text { related }\end{array}$ \\
\hline 22 & $\begin{array}{l}\text { Chiropodists/ } \\
\text { podiatrists }\end{array}$ & $\begin{array}{l}\text { The College of } \\
\text { Podiatry }\end{array}$ & March 2020 & $\begin{array}{l}\text { Professional body via } \\
\text { email }\end{array}$ & Generic & $\begin{array}{l}\text { Audio and video } \\
\text { consultations }\end{array}$ & Yes \\
\hline 23 & Dietitians & $\begin{array}{l}\text { NHS England and } \\
\text { NHS Improvement }\end{array}$ & April 2020 & $\begin{array}{l}\text { Professional body's } \\
\text { website }\end{array}$ & Generic & $\begin{array}{l}\text { Audio and video } \\
\text { consultations }\end{array}$ & Yes \\
\hline 24 & $\begin{array}{l}\text { Occupational } \\
\text { therapists }\end{array}$ & $\begin{array}{l}\text { Royal College } \\
\text { of Occupational } \\
\text { Therapists }\end{array}$ & May 2020 & $\begin{array}{l}\text { Professional body's } \\
\text { website }\end{array}$ & Generic & $\begin{array}{l}\text { Video consultations - } \\
\text { group sessions }\end{array}$ & Yes \\
\hline 25 & Orthoptists & $\begin{array}{l}\text { British and Irish } \\
\text { orthoptic society }\end{array}$ & April 2020 & Professional body & Generic & $\begin{array}{l}\text { Audio and video } \\
\text { consultations }\end{array}$ & Yes \\
\hline 26 & Osteopaths & $\begin{array}{l}\text { The Institute of } \\
\text { Osteopathy }\end{array}$ & April 2020 & $\begin{array}{l}\text { Professional body via } \\
\text { email }\end{array}$ & Generic & $\begin{array}{l}\text { Audio and video } \\
\text { consultations }\end{array}$ & Yes \\
\hline 27 & Physiotherapists & $\begin{array}{l}\text { The Chartered Society } \\
\text { of Physiotherapists }\end{array}$ & $\begin{array}{l}\text { May } 2020 \\
\text { (last review } \\
\text { December } \\
\text { 2020) }\end{array}$ & $\begin{array}{l}\text { Professional body's } \\
\text { website }\end{array}$ & Generic & $\begin{array}{l}\text { Audio and video } \\
\text { consultations }\end{array}$ & Yes \\
\hline 28 & $\begin{array}{l}\text { Prosthetists and } \\
\text { orthotists }\end{array}$ & $\begin{array}{l}\text { The British } \\
\text { Association of } \\
\text { Prosthetists and } \\
\text { Orthotists }\end{array}$ & April 2020 & $\begin{array}{l}\text { Professional body via } \\
\text { email }\end{array}$ & $\begin{array}{l}\text { Generic but provides } \\
\text { information about } \\
\text { the management of } \\
\text { knee OA, foot drop } \\
\text { and DVT requiring } \\
\text { compression hosiery }\end{array}$ & $\begin{array}{l}\text { Audio and video } \\
\text { consultations }\end{array}$ & Yes \\
\hline 29 & $\begin{array}{l}\text { Speech and } \\
\text { language } \\
\text { therapists }\end{array}$ & $\begin{array}{l}\text { The Royal College of } \\
\text { Speech and Language } \\
\text { Therapists }\end{array}$ & July 2020 & $\begin{array}{l}\text { Professional body via } \\
\text { a link directed to their } \\
\text { website }\end{array}$ & Generic & Video consultations & Yes \\
\hline
\end{tabular}

consultations to determine the appropriateness of this care modality. They recommended that the decision should be made on a case-by-case basis ${ }^{19} 31$ and should be dictated by professional judgement. ${ }^{19} 23263233$ Eighteen articles/guidelines reported that the decision should consider individual patient's characteristics to provide individualised care. ${ }^{34}{ }^{35}$ Details on patient's eligibility criteria for telehealth mentioned in the articles/ guidelines included in the review are provided in online supplemental file 3 .

\section{Clinicians' and patient's checklist}

Of the 29 included articles/guidelines, 11 articles (41\%, four from the UK AHP professional bodies) offered a clinician's and patient's checklist to guide telehealth consultations. In these articles/guidelines, a clinician's checklist with information to collect before, during and after the virtual consultation was present. A checklist for stated items AHPs should meet before, during and after

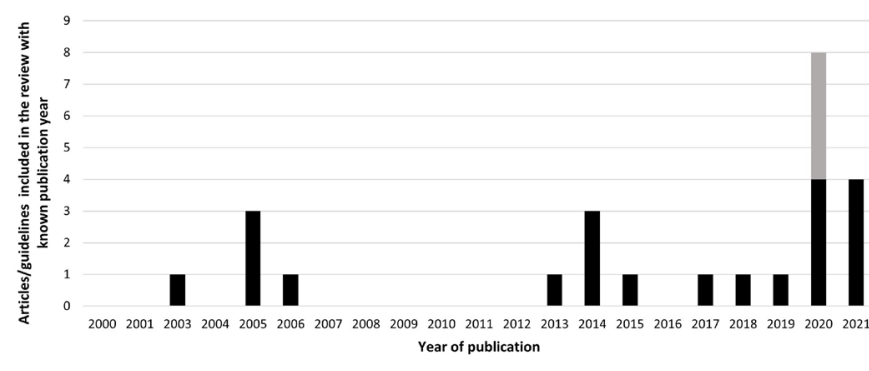

Figure 2 Scoping review search results by year of publication. AHP, allied health professional. a telehealth consultation is provided in online supplemental file 4 . The study by Wong $e t a \hat{l}^{2}$ was the only one that provided a checklist for patients attending a telehealth consultation.

\section{Patient information}

The patient information topic, which mainly composed of information about gaining consent for treatment, was discussed by 15 articles/guidelines (52\% of all included articles/guidelines), six of which were UK AHP professional body guidelines. Bierman et $a l,^{24}$ the $\operatorname{RCSLT}^{19}$ and Wong et $a \hat{l}^{2}$ stated that consent should be obtained at the beginning of the virtual session before starting the treatment. Six articles/guidelines ${ }^{1921} 24323637$ explained the nature of the consent with the manner of obtaining the consent (verbal,

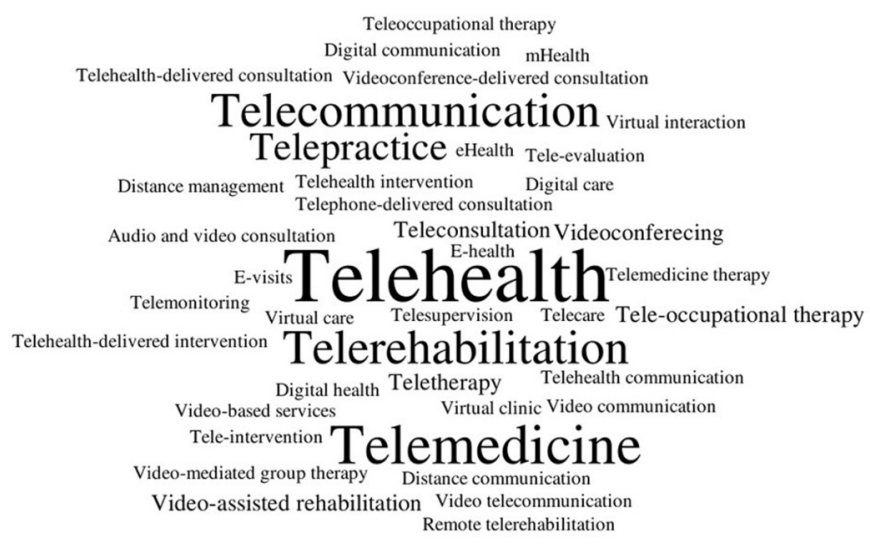

Figure 3 The telehealth terminology used across articles/ guidelines. 


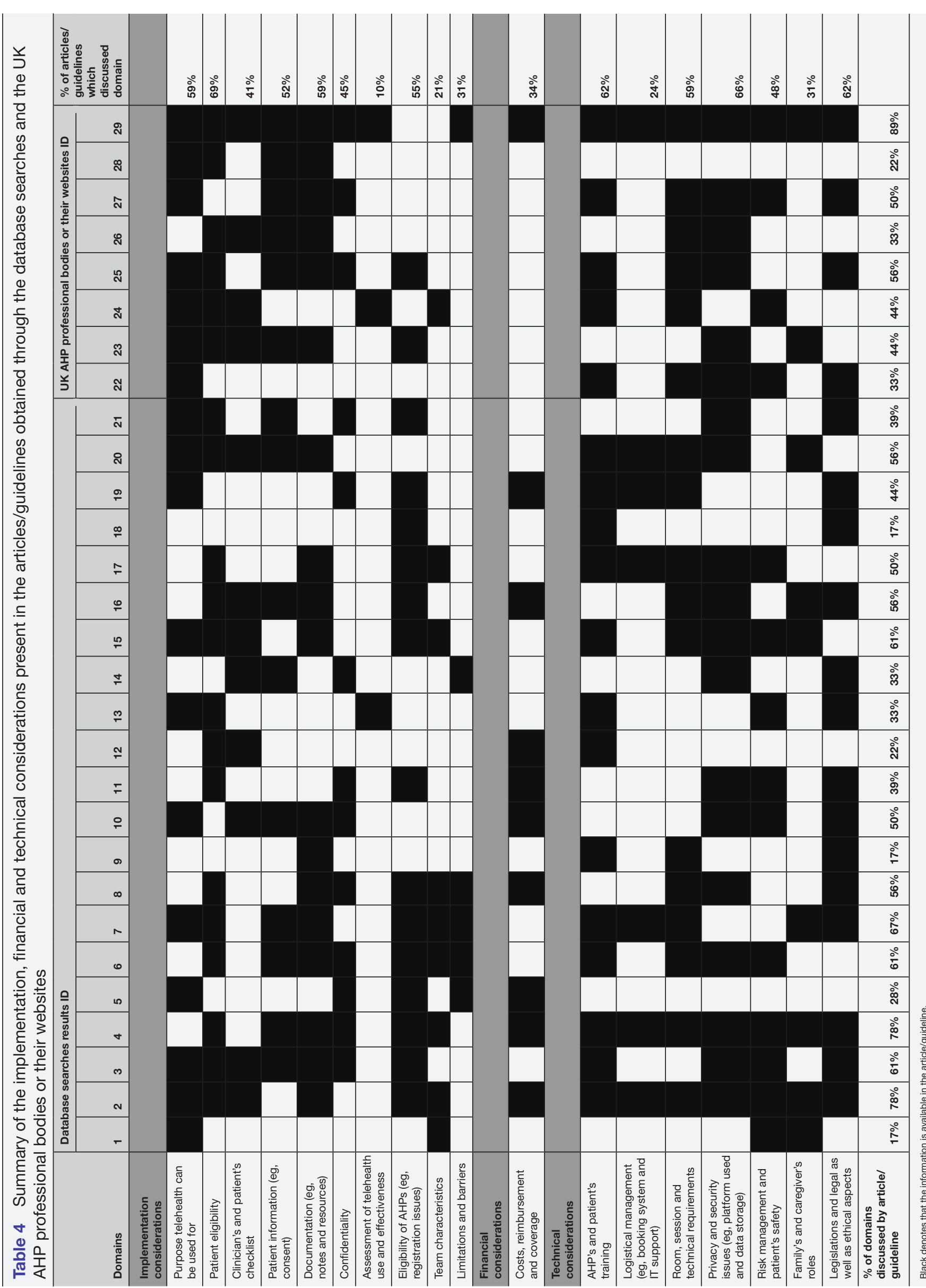

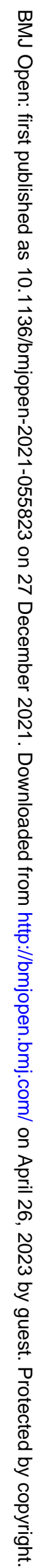


written or implicit consent by accepting to join the telehealth consultation) varying across articles/guidelines. Eight articles/guidelines ${ }^{19} 212526293238$ mentioned that AHPs should make patients aware of the risks and limitations associated with telehealth. Risks related to a potential breach of privacy, confidentiality and security were acknowledged in five articles/guidelines, ${ }^{19} 25262932$ limitations related to the assessments and treatments provided remotely in four ${ }^{21} 252632$ and other non-specified risks in two. ${ }^{2538}$ It was stated that patients should also be informed about the differences between telehealth and face-to-face consultations. ${ }^{25}{ }^{32}$ Four articles/ guidelines ${ }^{1936} 3739$ clarified that participation in a telehealth consultation is completely voluntary and that patients can refuse this mode of delivery. ${ }^{19}{ }^{39}$ In this case, it was stated that AHPs should offer alternative treatment options, ${ }^{19} 26$ which however may not be always available. ${ }^{36} 37$

\section{Documentation}

Seventeen articles/guidelines (59\% of all included articles/guidelines), six from UK AHP professional bodies, included documentation information. Four UK AHP professional body guidelines ${ }^{33}$ 36-38 reported that AHPs should record the consultation as it was a face-to-face appointment. Quigley et $a l^{29}$ stated that patient documentation should have a Subjective, Objective, Assessment and Plan note format. ${ }^{29}$ Ben-Ahron, ${ }^{20}$ the College of Podiatry ${ }^{36}$ and The Chartered Society of Physiotherapists ${ }^{37}$ also reported that subjective information and clinical outcomes should be documented, but no suggestion about the use of a structured format was provided. ${ }^{20} 3637$ Four articles/guidelines ${ }^{19} 242933$ mentioned that AHPs should specify in their notes that the consultation was delivered remotely. Two articles/guidelines ${ }^{33}{ }^{35}$ suggested that any limitations encountered during the consultation, either related to the assessment and treatment or to technology and safety, should be reported. Denton ${ }^{25}$ recommended AHPs to document the equipment used during the consultation, the people that took part in the virtual consultation and the reason behind their participation. ${ }^{25}$ It was recommended that any patient-related communication (eg, emails, tests and prescriptions) should be included in the patient's documentation. ${ }^{24}$ Six articles/ guidelines also mentioned the resources provided to the patient. ${ }^{18-20313540}$ These resources could be either digital in form of videos ${ }^{192031}$ or in writing as a leaflet ${ }^{18-20} 313540$ and can detail information about the consultation, ${ }^{18} 19$ how to do use a virtual platform ${ }^{19}$ and how to solve any possible technology issues. ${ }^{31}$

\section{Confidentiality}

Fourteen articles/guidelines (45\% of all included articles/guidelines), including four UK AHP professional body guidelines, contained recommendations about patient confidentiality protection.

\section{Assessment of telehealth use and effectiveness}

Three articles/guidelines (10\% of all included articles/ guidelines), ${ }^{19} 2228$ two of which are UK AHP professional body guidelines, ${ }^{1922}$ mentioned the use of a continuous monitoring process to evaluate the effectiveness of telehealth interventions. The RCSLT guideline ${ }^{19}$ from the UK was the only study to report the quality improvement strategies that can be adopted such as an online questionnaire and feedback from the patient and their family. ${ }^{19}$

\section{Eligibility of AHPS}

Most of the included articles $(55 \%, \mathrm{n}=16)$ and two of the UK AHP professional body guidelines ${ }^{23} 38$ had elements related to the AHPs' eligibility to conduct telehealth consultations. Eleven articles/guidelines $^{20} 24-272931$ 41-43 reported that AHPs must be registered practitioners to practice telehealth. However, the licensure and registration requirements varied across those articles/guidelines providing information about registration issues; ${ }^{20} 252729404244$ these were mainly from the USA 2527404244 and discussed issues around practising across different states. Two UK AHP professional body ${ }^{36} 38$ provided information regarding eligibility requirements during the COVID-19 pandemic. Telehealth was considered appropriate for AHPs who were self-isolating ${ }^{3638}$ and for those who can work from home using an approved organisational Information Governance system. ${ }^{38}$

\section{Characteristics of the team}

A small number of articles/guidelines $(21 \%, \mathrm{n}=10)$, with one from a UK AHP professional body, ${ }^{22}$ detailed the characteristics that a team providing telehealth should have. Five articles ${ }^{25} 34354045$ recommended that telehealth consultations should be conducted by a multidisciplinary team that includes physicians, AHPs, nurses and support personnel. One stated that other non-qualified facilitators can be involved in the provision of remote consultations. ${ }^{40}$ A triage team could support the service by prioritising patients based on their urgency. ${ }^{45}$ Similä et $a l^{42}$ Burns and Wall ${ }^{31}$ and the Royal College of Occupational Therapists $^{22}$ stated that telehealth services would benefit from the presence of a telehealth service coordinator and AHP digital leader to monitor the clinical, operational, technical and financial aspects of the service and promote collaboration with other local stakeholders. ${ }^{22} 3142$

\section{Limitations and barriers}

Six articles/guidelines (31\% of all included articles/ guidelines), ${ }^{192539404445}$ including one guideline from a UK AHP professional body, ${ }^{19}$ acknowledged barriers and limitations associated with remote consultations, which appear to pertain to different telehealth aspects. Denton ${ }^{25}$ and Cason ${ }^{44}$ recognised the potential multistate licensure requirements and the attached application and renewal fees as potential barriers to telehealth. ${ }^{25} 44$ The nature of telehealth was seen as a limitation as it may affect the communication ${ }^{19}$ and the relationship between the patient and the treating clinician, ${ }^{39}$ which may lead the patient to experience alienation feelings. ${ }^{40}$ The nature of the remote consultations that can limit the AHPs' ability to perform hands-on patient assessment and treatment was also discussed. ${ }^{45}$ 
Financial considerations

\section{Costs, reimbursement and coverage}

Ten articles $(34 \%$ of all included articles/guidelines), ${ }^{19-21} \quad 26$ 29-31 $4144 \quad 45$ including a UK AHP professional body guideline, ${ }^{19}$ explored the financial aspects associated with telehealth. Two articles/guidelines 1930 mentioned the telehealth service costs. While Kelly et $a l^{30}$ stated that telehealth consultations should be cost neutral, ${ }^{30}$ the RCSLT guideline ${ }^{19}$ reported that the consultation fees may be different compared with face-to-face appointments due to overheads and possible increased planning time. ${ }^{19}$ Five articles/guidelines 2627314144 provided information about the reimbursement process. Jacobs et al, ${ }^{41}$ Burns and Wall ${ }^{31}$ and the World Federation of Occupational Therapists ${ }^{26}$ stated that AHPs and the telehealth providing sites must adhere to the reimbursement requirements. ${ }^{263141}$ Burns and Wall ${ }^{31}$ specified that this should happen even if they cross different healthcare services, states or countries. ${ }^{31}$ Coverage for telehealth services was discussed in four articles/guidelines. ${ }^{20} 294445$ Ben-Aharon ${ }^{20}$ and Quigley et $a l^{29}$ stated that the patient's insurance company should be contacted to determine whether it offers telehealth coverage. $^{2029}$

\section{Technical considerations}

\section{AHPs' and patient's training}

Eighteen articles/guidelines (62\% of all included articles/guidelines), with five UK AHP professional body guidelines, ${ }^{19} 22$ 36-38 acknowledged training for AHPs and/or patient as a requirement for telehealth consultations. Many of the articles/guidelines $(n=11)$ mentioned that technology training is an essential competency for AHPs only. Six articles, ${ }^{19} 2832$ 36-38 four from the UK AHP professional bodies, ${ }^{19}$ 36-38 mentioned that both AHPs and patients should be competent in the use of technology communication for remote consultations. In one article, ${ }^{35}$ patients were considered the only ones requiring technology training for telehealth. In addition to the technological skills, two articles ${ }^{28} 42$ reported that AHPs should be trained in responding to unexpected situations. Seven articles/guidelines ${ }^{24} 3031$ 36-38 mentioned that AHPs should also be involved in continuing professional development training programmes. Of those articles/guidelines recognising the importance of training for patients $(n=7)$, four articles/guidelines, ${ }^{35-38}$ of which three were UK guidelines, ${ }^{36-38}$ suggested that clinicians conduct a telehealth trial with those patients less familiar with technology to coach them to use technology communications prior to the consultation.

\section{Logistical management}

Logistic support was considered an integral part of the telehealth services by seven articles/guidelines (24\% of all included articles/guidelines), ${ }^{19} 202527313242$ including one from a UK AHP professional body. ${ }^{19}$

\section{Room, session and technical requirements}

Room, session and technical requirements of telehealth consultations were detailed in 17 articles $(59 \%$ of all included articles/guidelines), with six from UK AHP professional bodies. ${ }^{192233 \text { 36-38 }}$ Half of the articles/guidelines $(n=15)$ provided information about the technical requirements for telehealth. $17192025272931-333538404245$ Eight articles informed AHPs about the room requirements, ${ }^{19} 20323335363842$ and five articles included information about the session characteristics. ${ }^{19} 31354042$

The technical recommendations varied across the articles/guidelines. The availability of a reliable and highspeed internet connection was considered a necessary requirement by four articles/guidelines. ${ }^{20252732}$ However, Wakeford et $a l^{27}$ specified that low-speed connection is still acceptable for routine observations and interview. Four articles/guidelines mentioned the use of secure and approved platforms. ${ }^{1922} 2935$

The room requirements differed between articles/ guidelines but included some common requirements. The most common recommendations for both AHPs and patients were: (1) to use a well-lighted environment; ${ }^{20323342}$ (2) to use a reasonably private room 20323342 with minimal distraction; ${ }^{20} 3242$ and (3) to use a notice on the room door indicating that a consultation is taking place. $^{32} 333638$ This last recommendation was mainly present in UK guidelines $(n=3) .^{33} 3638$ With regards to the session requirements, all articles/guidelines provided information about the equipment needed for consultations.

\section{Privacy and security issues}

Eighteen articles/guidelines (66\% of all included articles/guidelines), including most of the UK AHP professional body guidelines $(n=6),{ }^{19} 2333$ 36-38 discussed the aspects concerning the privacy and security of telehealth consultations. Ten articles/guidelines ${ }^{21} 26 \quad 31 \quad 32 \quad 36 \quad 38-42$ stated that AHPs must protect their patient's privacy and ensure information security during data transmission and storage. Burns and Wall ${ }^{31}$ specified that technology and data security should be guaranteed by all participating sites, even if they cross different health services, states and countries. ${ }^{31}$ Eight articles/guidelines 20232932353845 reported that telehealth consultations should take place using safe and secure platforms ensuring data privacy and security. Three UK guidelines ${ }^{33} 3637$ specified that AHPs should not use commercial apps and private messaging services of social media platforms unless there are no alternative communication means and the benefits overweight the risks. Five articles/guidelines ${ }^{32} 36-3846$ provided guidance on password and authentication best practices.

\section{Risk management and patient's safety}

Aspects related to risk management and patient safety were present in 15 articles/guidelines ( $48 \%$ of all included articles/guidelines), four from the UK. ${ }^{1923} 36$ Additionally, two articles ${ }^{19} 40$ reported that the procedures to follow in case of technical disruption or emergency should be 
clearly outlined. To manage potential unforeseen circumstances, four articles/guidelines ${ }^{19} 212440$ stated that AHPs should ensure they have a patient's personal contact, ${ }^{19} 40$ an alternative communication means, ${ }^{24}$ and the physical location of the patient at the time of the consultation. ${ }^{21}$

\section{Family's and/or caregiver's role}

Nine articles/guidelines (31\% of all included articles/ guidelines), ${ }^{19} 2023252931323435$ of which two were UK AHP professional body guidelines, ${ }^{19}{ }^{23}$ identified the role of the patient's family and caregiver in supporting telehealth consultations.

\section{Legislation, legal and ethical aspects}

Topics pertaining to legislation, legal and ethical principles of telehealth consultations were contained in 19 articles/guidelines $(62 \%$ of the included articles/guidelines), with four from UK AHP professional bodies. ${ }^{196-38}$ Three articles ${ }^{20} 2143$ recommended AHPs to check prior to telehealth consultations whether remote consultations are permitted by law in their jurisdiction. Additionally, 12 articles/guidelines ${ }^{21}$ 25-28 31 37-3941 4445 reported that AHPs should be compliant with the relevant jurisdictional, local, national, institutional and professional regulations and policies governing telehealth. As telehealth regulations and policies often differ between countries and can vary within the same country between different states, ${ }^{24}$ three articles $^{25} 2844$ recommended AHPs to adhere to the requirements of the country/state where they physically are and to those existing in the state/country where the patient is at the time of the consultation. Six articles, ${ }^{17} 26-283943$ with none from the UK AHP professional bodies, reported that AHPs must adhere to a code of ethics.

\section{DISCUSSION}

This scoping review aimed to provide an overview of the information contained in telehealth guidelines for AHPs to identify key recommendations on the use of telehealth for AHP patient consultations.

\section{Characteristics of included articles/guidelines}

Most of the articles were published in the USA, followed by Canada and Australia. This finding may be attributable to the morphology and the geographical distribution of the resources in these countries ${ }^{47}$ where telehealth has been used for decades by healthcare professionals to reach remote and isolated communities. The telehealth standards proposed by these articles are also the reflection of the healthcare systems, the requirements to practice and socioeconomic values of these countries. Therefore, they may not be implemented in those nations whose healthcare systems operate differently, where the registration requirements to provide telehealth as an AHP are diverse, and in lower socioeconomic countries, which may not have the resources to use the standards from developed countries and therefore need guidance appropriately matching their own resources. This review demonstrated that telehealth is a new and emerging area of research with all the articles/guidelines in this area published in the past two decades and half of them within the last twoyears. Together with technological innovations, the COVID-19 pandemic seems to have driven research in this field reflecting the increased use of technology for healthcare purposes. While all the guidelines identified through the UK AHP professional bodies, or their websites, were produced in response to the COVID-19 pandemic, only five of the 21 articles identified through the database searches were. When considering those articles produced before the current pandemic, it should be noted that the demographics of the patients undertaking telehealth consultations has changed significantly due to the pandemic. All of the articles/guidelines, bar one, ${ }^{20}$ were produced for public AHP services. However, the pandemic-driven shift has affected both public and private AHP services with remote consultations and telehealth being the norm in private sector healthcare facilities, including large hospitals and small clinics. Therefore, future guidelines should also consider the needs of private service providers to support AHPs in the possible long-term implementation of telehealth.

Most of the articles were categorised as level 5 of evidence, which corresponds to the study designs considered acceptable to achieve the objectives of this review. Most of the articles/guidelines were published to guide occupational therapists, physiotherapists and speech and language therapists with a limited number of articles/ guidelines for art therapists, dietitians, orthoptists, osteopaths, prosthetists and orthotists, and chiropodists/podiatrists. There were no guidelines specifically designed for drama therapists, music therapists, operating department practitioners, paramedics and radiographers. This indicates that most of the guidelines were produced by the larger professional bodies, and this may be due to potential inequity in personnel and resources. Urgent action is required from AHP professional bodies without guidelines for telehealth as they would improve the delivery and the quality of AHP services.

Although telehealth was the most frequently used term in the literature, a variety of terminology has been used across the articles/guidelines. Therefore, there is a need to standardise terminology associated to telehealth. Most of the included articles/guidelines were not disease or clinical population specific. However, telehealth is not a one-size-fits-all solution, and its applications need to be customised to accommodate the needs of a diverse range of populations. ${ }^{48}$ Therefore, this finding suggests that the current telehealth guidelines may not fully capture the complex care needs of specific population groups, for which telehealth consultations may be neither safe nor effective.

Implementation, financial and technical considerations Telehealth considerations were grouped into implementation, financial and technical domains, which provided 
clear and explicit identification of the gaps in the guidelines that need to be addressed.

\section{Implementation considerations}

While some articles/guidelines reported that telehealth should only be adopted for follow-up appointments, ${ }^{20} 31$ considering that AHPs may have very limited or no capacity to conduct in-person assessments due to the COVID-19 restrictions, there is a need to identify possible compensatory measures to adopt in order to ensure that remote assessments are equally safe and effective as face-to-face evaluations in case the former option is not available.

Most of the articles/guidelines provided information related to the patient eligibility requirements; however, these indications may have led to the exclusion of certain clinical populations with more complex needs that cannot be met by telehealth. Additionally, it was suggested that the decision to offer patients telehealth appointments had to be made on a case-by-case basis ${ }^{19}{ }^{31}$ and dictated by individual professional judgement. ${ }^{193263233}$ However, clinicians may attempt to stretch the technological limits of telehealth and unintendedly expose themselves to a greater risk of malpractice and patients to risk of harm. Therefore, given that the generic nature of the personal requirements left the question of the telehealth eligibility open to personal interpretation, decision aids specific for possible clinical scenarios, as those present in the guidelines from BAPO,${ }^{18}$ would be useful adjuncts to the AHPs' decision-making process and would help AHPs offer telehealth only to those patients for whom it is appropriate. A more general framework detailing telehealth individual, organizational and system principles, as that recently proposed by Greenhalgh $e t a l,{ }^{49}$ would represent another valid tool to help AHPs make ethically sound decisions and offer high-quality remote consultations.

The lack of guidance for AHPs on the delivery of telehealth consultations was also clear from the limited guidance related to the clinicians' and patient's checklist. ${ }^{28}$ However, it should be noticed that checklists for telehealth consultations may be available in the form of online resources, and they may have been missed in this study due to our search strategy. ${ }^{50}$ Future research is needed to explore the essential steps patients need to complete prior to attending remote consultations, which should be incorporated into the guidelines for wider reach and for their potential to limit inconvenience during consultations and improve patients' experiences, especially for those who are less familiar with technology.

It is good practice to seek a patient's consent before any telehealth consultation, and this is also acknowledged by guidelines developed for non-AHP healthcare professionals. ${ }^{5253}$ Although the AHP guidelines are in line with these findings, as there was consensus about the need to gain consent from patients, there was no agreement as to how the consent should be obtained. This requires attention and clarification because obtaining appropriate consent can be the key to defending any claims of malpractice and negligence. No generalised clear instructions about the format for documentation information to follow, and the information to document were provided. Although most of the UK AHP professional bodies' guidelines reported that AHPs should record the consultation as they would do for a face-to-face appointment, ${ }^{336-38}$ clear and explicit guidance on this process is needed in the UK as well as worldwide to prevent documentation deficiencies and avoid future legal problems for AHPs.

The assessment of telehealth use and effectiveness received limited discussion. This indicates that AHP service managers should implement programme monitoring strategies for AHP services, as an ongoing process of assessment. This monitoring and review are essential to ensure the appropriateness and effectiveness of a service's provision. NHS England, for example, encourage clinicians to conduct self-audit of consultations, obtain daily feedback from other staff and patients, monitor impact on their workloads, hold regular team meetings and assess the effectiveness of processes/protocols. ${ }^{54}$

Another telehealth aspect that has not received much attention in the existing literature and UK guidelines was the clinical and technical staff involved in the telehealth team. The involvement of a multidisciplinary team and new roles (eg, telehealth service coordinator and an AHP digital leader) in the delivery of telehealth are beneficial to establish collaborative relationships across the different AHP professions at a national and international level and promote cooperative telehealth activities.

While most of the articles/guidelines covered aspects related to the AHPs' eligibility and there was consensus that AHPs must be registered practitioners to practice telehealth, it remains controversial whether AHPs should be registered only in the state/country where they reside and/or the service is provided, or also in the jurisdiction where the patient is. Therefore, there is an urgent need to clarify the registration requirements and governance compliance for AHPs in relation to the regional jurisdictions. The lack of international telehealth regulations can limit AHPs' legal liability when telehealth is practised across state/county lines. Also, this might leave gaps, potentially allowing acts of malpractice. While telehealth limitations and barriers received limited discussion, patients need to be informed about telehealth limitations and barriers to allow them to make an informed decision. ${ }^{19} 212526293238$ Therefore, limitations and barriers should be acknowledged and recognised as an integral part of the AHP guidelines in the UK and worldwide. Appropriately setting patients' expectations in telehealth consultations would help avoid their reactions to unmet expectations (eg, disappointment and anger), enhance their compliance and telehealth experience and, subsequently, reduce AHPs' exposure to liability.

\section{Financial considerations}

There were large areas of unclarity and ambiguity across the articles/guidelines regarding the costs, reimbursement and coverage aspects of telehealth. Information 
obtained from a recent freedom of information request to clinical commissioning groups (CCGs) in England identified that there are currently discrepancies in payment for AHP services between face-to-face and non-face-toface consultations; some CCGs stated they were paying the same amount regardless of the method of delivery and some stated they were paying over fourfold more for a face-to-face appointment. Defining the time and the personnel that need to be involved in telehealth consultations may potentially clarify the telehealth service charge. Such clarifications may subsequently provide insurance companies with greater incentives to consider coverage for telehealth, which is still under debate in the current few articles/guidelines containing this aspect.

\section{Technical considerations}

With limited guidance on session requirements, for example, no information was provided about the recommended length of remote consultations, which remains unknown, and these needs to be defined for clinical safety and resource purposes. Despite variation across articles/ guidelines with some common points still present, the room and technical requirements appeared to reflect the principles of privacy, security and confidentiality that were largely considered in the articles/guidelines included in the review. The requirements of a reliable and high-speed internet connection, together with safe and secure platforms, explicitly preferred to commercial apps in the UK, ${ }^{33} 3637$ may affect telehealth use in poor rural communities with low bandwidth and where AHP services may have a limited budget to cover the expenses of a private platform.

Although telehealth guidelines for patient consultations developed for non-AHP healthcare professionals include a risk management plan within their recommendations, ${ }^{55}$ risk management strategies are not widely described in the AHP guidelines, and no patient safety procedure is available yet. A common plan of action needs to be developed by the AHP professional bodies, in the UK as well as in the rest of the world, to help their members cope with any unforeseen events and to mitigate the impact of these unexpected occurrences on patients to prevent or limit patient harm. ${ }^{29} 3233$

It is considered best practice to engage patient's family and caregivers to ensure optimal and patient-centred care. ${ }^{56}$ Despite this, there was a limited number of articles/guidelines that recognised the role the patient's family and/or caregiver's play in the care provision, ${ }^{19} 23$ or mentioned the presence of either family or caregiver support as a potentially necessary in case of patients requiring physical, cognitive and emotional support. ${ }^{202931}$ In case of their unavailability or if patients are socially isolated, these vulnerable clinical populations may be excluded from telehealth, which may result in them not receiving care if telehealth is the only available option.

Most of the articles/guidelines detailing legislation and the legal aspects of telehealth stated that AHPs should comply with relevant jurisdictional, local, national, institutional, institutional and professional regulations and laws, it is still unclear whether AHPs need to adhere to the legislations in their state/country or also comply with those in place in patient's jurisdiction. Therefore, a global and generic minimum standard to practice telehealth worldwide and universal regulations and policies should be set and eventually be adapted to the different local contexts. Uniformity in telehealth regulations will contribute to facilitating insurers and policymakers to reimburse telehealth services within and across countries.

To the authors' knowledge, this is the first study to review the literature containing guidelines for the use of telehealth for patient consultations in AHP services and compared them with the guidelines developed by the UK AHP professional bodies. It offers a comprehensive identification and summary of the telehealth implementation, financial and technical considerations present in the currently available articles/guidelines. This provides AHP services, AHP professional bodies, guideline developers and policy makers with a comprehensive and detailed overview of the considerations that AHPs should be concerned about when using telehealth for patient consultations. Implementing these considerations in clinical practice could prevent and reduce risks, errors and harm that occur to patients during the provision of AHP services via telehealth and their potential consequent serious injuries and fatalities. The findings of this study have also the potential to inform the development of a framework with implementation, financial and technical considerations regarding the use of telehealth in UK AHP services. This may help UK AHP professional bodies and services adopt a common line of action and, consequently, is likely to contribute to address the existing inequalities among UK AHPs.

Potential limitations of this study include only articles written in English were examined and, as a result, relevant publications in a language other than English may have been missed. Additionally, only articles characterised by specific methodological designs containing telehealth guidelines within their abstract and/or full text were considered eligible for review. This may have led to the exclusion of articles with study designs, other than those deemed appropriate for this study, which however contained guidelines for remote consultations with patients. Similarly, the limiting of the grey literature search to the guidelines sourced from UK AHP professional bodies or their websites may have led to potentially relevant resources being missed. Although any uncertainty in data extraction and study inclusion was resolved through discussion with a second reviewer and if required the wider team, these study phases were performed independently by one reviewer, whose personal bias may have impacted these processes. Patients, public and experts in the field were not involved in any stages of the research, and therefore, the findings of this study do not represent the patient and professional user experiences of telehealth. 
This scoping review has explored the currently available guidelines for AHPs using telehealth for patient consultations. The review has established that telehealth has emerged as a new area of research in the last decades, which has been boosted ever further by the COVID-19 pandemic. Although telehealth has been discussed in a considerable number of articles/guidelines, most of them were specifically designed for occupational therapists, physiotherapists and speech and language therapists, leaving the other AHPs with limited or no guidelines. This suggests the presence of inequalities among AHP groups. Similarly, some articles/guidelines have been specifically designed for certain clinical populations, and this may suggest that telehealth consultations need to be tailored to meet patients' individual needs. A great variety of terminology has been used to refer to telehealth. Although telehealth remains the most used term across the articles/guidelines, there is a need to standardise the telehealth terminology and its definitions. There was information lacking around some topics such as the assessment of telehealth use and effectiveness, telehealth barriers and limitations, the logistical management, the family's as well as caregiver's roles and the financial considerations in the included articles/guidelines. Additionally, there were some areas of unclarity and ambiguity, such as AHPs' eligibility, telehealth costs and coverage and legislation as well as legal aspects. Future guidelines should consider and provide a clearer description of these aspects as they have the potential to reduce patient harm and suffering and any consequent disabilities and deaths, thereby ensuring better patient outcomes, reducing risk of liability for clinicians and increasing financial savings for healthcare systems worldwide.

Following the results of this review, we have identified issues with the current telehealth guidelines that need to be addressed, and we recommend that the following actions be undertaken:

- Currently available AHP articles/guidelines do not adequately support AHPs delivering telehealth consultations. Future studies and guideline developers need to consider those telehealth topics lacking across articles/guidelines and address the large areas of unclarity and ambiguity present.

- Telehealth implementation considerations are considered equally as important as the technical considerations to guarantee that remote consultations do not reduce clinical benefits or create unintended risks to patients, consider and meet patients' and AHPs' needs and offer an integrated approach to clinical management.

- All of the UK AHP professional bodies' guidelines were designed to quickly respond to the need of standards for telehealth-mediated patient consultations during the COVID-19 pandemic. Therefore, the available guidelines should be reviewed to ensure they meet the long-term needs of patient consultations delivered through telehealth.

- There is a clear and immediate need to solve the existing inequalities among AHP professional bodies to avoid a direct impact on the services they offer, which inevitably affects the quality of care that their patients receive.

- AHP professional bodies should work together, in the UK as well as worldwide, to design common lines of action and telehealth guidelines.

- There is an urgent and immediate call for unilateral initiatives from organisations such as the WHO to provide universally valid guidelines for telehealth consultations to support AHP services across the world, enhance their quality and address regulation and malpractice issues arising from AHP services provided across states/countries.

\section{CONCLUSION}

This study provides an overview of the current AHP guidelines on the use of telehealth for patient consultations and compared them with the UK AHP guidance, thereby identifying the gaps between published literature and actual requirements for telehealth consultations. Results reveal that the current guidelines for telehealth have similarities as well as discrepancies in respect to the guidance for non-AHP healthcare professionals which, however, appear to be more extensive, better structured and more developed documents. Therefore, the current AHP telehealth guidelines appear not to adequately support AHPs in the delivery of remote consultations via telehealth. Future research and collaborative efforts across AHP professional bodies and the world's leading health institutions are needed to solve the areas of unclarity and ambiguity. Establishing global telehealth guidelines that can be adapted to local contexts could mitigate avoidable harm or risk of harm and limit adverse events resulting from telehealth, thereby preventing patients from receiving unsafe care and leading to improvements in quality of AHP service provision.

\section{Author affiliations}

${ }^{1}$ Centre for Biomechanics and Rehabilitation Technologies, Staffordshire University, Stoke-on-Trent, UK

${ }^{2}$ Orthotic Service, The Royal Wolverhampton NHS Trust, Wolverhampton, UK ${ }^{3}$ Dorset County Hospital NHS Foundation Trust, Dorchester, UK

Twitter Enza Leone @leone_enza, Aoife Healy @AoifeCHealy and Nachiappan Chockalingam @nachic

Contributors All authors conceived the idea and contributed to the study design of the review. EL carried out the literature search, and CR contacted the UK allied health professional (AHP) bodies to request their guidelines. Inclusion and exclusion of full-text articles was reached by consensus by $E L$ and $A H$, in case of disagreement on eligibility between the two reviewers, then the article was discussed with the other coauthors (NE, CR and NC). Data were extracted and analysed by EL. All the authors have made a significant contribution to drafting the manuscript and have seen and approved the final manuscript. EL, NE and AH contributed equally to this paper. NC is the manuscript's guarantor.

Funding The study was supported by Public Health England through the British Association of Prosthetists and Orthotists (BAP0), Ref: 6719098 (02.02.21).

Competing interests None declared.

Patient consent for publication Not applicable.

Provenance and peer review Not commissioned; externally peer reviewed. 
Data availability statement Data are available on reasonable request. All data generated or analysed during this study are included in this published article and its additional information files. Should further details be required, please contact the corresponding author.

Supplemental material This content has been supplied by the author(s). It has not been vetted by BMJ Publishing Group Limited (BMJ) and may not have been peer-reviewed. Any opinions or recommendations discussed are solely those of the author(s) and are not endorsed by BMJ. BMJ disclaims all liability and responsibility arising from any reliance placed on the content. Where the content includes any translated material, BMJ does not warrant the accuracy and reliability of the translations (including but not limited to local regulations, clinical guidelines, terminology, drug names and drug dosages), and is not responsible for any error and/or omissions arising from translation and adaptation or otherwise.

Open access This is an open access article distributed in accordance with the Creative Commons Attribution Non Commercial (CC BY-NC 4.0) license, which permits others to distribute, remix, adapt, build upon this work non-commercially, and license their derivative works on different terms, provided the original work is properly cited, appropriate credit is given, any changes made indicated, and the use is non-commercial. See: http://creativecommons.org/licenses/by-nc/4.0/.

\section{ORCID iDs}

Aoife Healy http://orcid.org/0000-0002-4948-6086

Nachiappan Chockalingam http://orcid.org/0000-0002-7072-1271

\section{REFERENCES}

1 World Health Organization. Telemedicine: opportunities and developments in member states: report on the second global survey on eHealth. 93. World Health Organization, 2010. https://www.who. int/goe/publications/goe_telemedicine_2010.pdf

2 Strehle EM, Shabde N. One hundred years of telemedicine: does this new technology have a place in paediatrics? Arch Dis Child 2006;91:956-9.

3 Gajarawala SN, Pelkowski JN. Telehealth benefits and barriers. J Nurse Pract 2021;17:218-21.

4 Kelion L. Babylon health admits GP APP suffered a data breach. BBC news, 2020. https://www.bbc.co.uk/news/technology-52986629

5 Resneck JS, Abrouk M, Steuer M, et al. Choice, transparency, coordination, and quality among direct-to-consumer telemedicine websites and apps treating skin disease. JAMA Dermatol 2016;152:768-75.

6 Graham ID, Harrison MB. Evaluation and adaptation of clinical practice guidelines. Evid Based Nurs 2005;8:68-72.

7 Monaghesh E, Hajizadeh A. The role of telehealth during COVID-19 outbreak: a systematic review based on current evidence. BMC Public Health 2020;20:1193.

8 Mann DM, Chen J, Chunara R, et al. COVID-19 transforms health care through telemedicine: evidence from the field. J Am Med Inform Assoc 2020;27:1132-5.

9 Rushforth A, Greenhalgh T, Medicine P. Personalized medicine, disruptive innovation, and "trailblazer" guidelines: case study and theorization of an unsuccessful change effort. Milbank $Q$ 2020;98:581-617.

10 Krupinski EA, Bernard J. Standards and guidelines in telemedicine and telehealth. Healthcare 2014;2:74-93.

11 Levac D, Colquhoun H, O'Brien KK. Scoping studies: advancing the methodology. Implement Sci 2010;5:69.

12 Arksey H, O'Malley L. Scoping studies: towards a methodological framework. Int J Soc Res Methodol 2005;8:19-32.

13 Tricco AC, Lillie E, Zarin W, et al. PRISMA extension for scoping reviews (PRISMA-ScR): checklist and explanation. Ann Intern Med 2018;169:467-73.

14 NHS England and NHS Improvement. The 14 allied health professions. Available: https://www.england.nhs.uk/ahp/role

15 NSW Agency for Clinical Innovation. Guidelines for the use of telehealth for clinical and non clinical settings in NSW, 2015. Available: https://www.telemedicine-360.com/wp-content/uploads/ 2019/02/2015-ACl-telehealth-guidelines.pdf

16 Wright JG, Swiontkowski MF, Heckman JD. Introducing levels of evidence to the Journal. J Bone Joint Surg Am 2003;85:1-3.

17 Hailey D, Foerster V, Nakagawa B, et al. Achievements and challenges on policies for allied health professionals who use telehealth in the Canadian Arctic. J Telemed Telecare 2005;11 Suppl 2:39-41.

18 The British Association of Prosthetists and Orthotists (BAPO. Guidelines for virtual patient assessment, 2020. Available: https://
www.bapo.com/wp-content/uploads/2020/04/BAPO-VirtualAssessment-Guidelines-compressed.pdf

19 The Royal College of Speech and Language Therapist - RCSLT. Telehealth guidance, 2020. Available: rcslt.org/members/deliveringquality-services/telehealth/telehealth-guidance/

20 Ben-Aharon A. A practical guide to establishing an online speech therapy private practice. Perspect ASHA Spec Interest Groups 2019;4:712-8.

21 Haldeman S, Nordin M, Tavares P, et al. Distance management of spinal disorders during the COVID-19 pandemic and beyond: evidence-based patient and clinician guides from the global spine care initiative. JMIR Public Health Surveill 2021;7:e25484.

22 Royal College of Occupational Therapists. Digital occupational therapy, 2020. Available: rcot.co.uk/practice-resources/occupationaltherapy-topics/digital-first-occupational-therapy

23 NHS England and NHS Improvement. Novel coronavirus (COVID-19) standard operating procedure: community health services NHS England and NHS improvement, 2020. Available: https://www.bda. uk.com/uploads/assets/7f380e35-5679-4ade-9c5fdabea64ba108/ C0198-community-health-services-sop.pdf

24 Bierman RT, Kwong MW, Calouro C. State occupational and physical therapy telehealth laws and regulations: a 50 -state survey. Int $J$ Telerehabil 2018;10:3-54.

25 Denton DR. Ethical and legal issues related to telepractice. Semin Speech Lang 2003;24:313-22.

26 World Federation Of Occupational Therapists. World federation of occupational therapists' position statement on telehealth. Int $J$ Telerehabil 2014;6:37-9.

27 Wakeford L, Wittman PP, White MW, et al. Telerehabilitation position paper. Am J Occup Ther 2005;59:656-60.

28 Lee AC. COVID-19 and the advancement of digital physical therapist practice and telehealth. Phys Ther 2020;100:1054-7.

29 Quigley A, Johnson $\mathrm{H}$, McArthur C. Transforming the provision of physiotherapy in the time of COVID-19: a call to action for telerehabilitation. Physiotherapy Canada 2021;73:1-2.

30 Kelly JT, Allman-Farinelli M, Chen J, et al. Dietitians Australia position statement on telehealth. Nutr Diet 2020;77:406-15.

31 Burns CL, Wall LR. Using telepractice to support the management of head and neck cancer: key considerations for speech-language pathology service planning, establishment, and evaluation. Perspect ASHA Spec Interest Groups 2017;2:139-46.

32 Wong A, Bhyat R, Srivastava S, et al. Patient care during the COVID-19 pandemic: use of virtual care. J Med Internet Res 2021;23:e20621.

33 The Institute of Osteopathy. A guide to telephone and video consultations in osteopathic practice, 2020.

34 Bamaga AK, Alghamdi F, Alshaikh N, et al. Consensus statement on the management of duchenne muscular dystrophy in Saudi Arabia during the coronavirus disease 2019 pandemic. Front Pediatr 2021;9:629549.

35 Middleton A, Simpson KN, Bettger JP, et al. COVID-19 pandemic and beyond: considerations and costs of telehealth exercise programs for older adults with functional impairments living at home-lessons learned from a pilot case study. Phys Ther 2020;100:1278-88

36 The College of Podiatry. Guidance on remote consultations, 2020.

37 The Chartered Society of Physiotherapists (CSP). COVID-19: guide for rapid implementation of remote physiotherapy delivery. Journal of Medical Internet Research 2020;20.

38 British and Irish Orthoptic Society (BIOS). COVID-19 bios update advice for telephone consultations and social distancing, 2020. Available: https://www.graybrook.co.uk/bios-members

39 Meredith G, Firmin S, McAllister L. Digital possibilities and ethical considerations: speech-language pathologists and the web. Journal of Clinical Practice in Speech-Language Pathology 2013;15:44-7.

40 Collie K, Bottorff JL, Long BC, et al. Distance art groups for women with breast cancer: guidelines and recommendations. Support Care Cancer 2006;14:849-58

41 Jacobs K, Cason J, McCullough A. The process for the formulation of the international telehealth position statement for occupational therapy. Int J Telerehabil 2015;7:21-32.

42 Similä $\mathrm{H}$, Harjumaa $\mathrm{M}$, Isomursu $\mathrm{M}$, et al. Video communication in remote rehabilitation and occupational therapy groups. Phys Occup Ther Geriatr 2014;32:97-111.

43 Waguespack $\mathrm{G}$. The regulation of telepractice in the profession of audiology. Semin Hear 2005;26:53-5.

44 Cason J. Telehealth: a rapidly developing service delivery model for occupational therapy. Int J Telerehabil 2014;6:29-36.

45 Doll EJ, Braden MN, Thibeault SL. COVID-19 and speech-language pathology clinical practice of voice and upper airway disorders. Am J Speech Lang Pathol 2021;30:63-74. 
46 Meredith G, Firmin S, McAllister L. Digital possibilities and ethical considerations. Journal of Clinical Practice in Speech-Language Pathology 2015;17:42-5.

47 Palozzi G, Schettini I, Chirico A. Enhancing the sustainable goal of access to healthcare: findings from a literature review on telemedicine employment in rural areas. Sustainability 2020;12:3318.

48 Alverson DC, Holtz B, D'lorio J, et al. One size doesn't fit all: bringing telehealth services to special populations. Telemed J E Health 2008;14:957-63.

49 Greenhalgh T, Rosen R, Shaw SE, et al. Planning and evaluating remote consultation services: a new conceptual framework incorporating complexity and practical ethics. Front Digit Health 2021;3:726095.

50 Allied Health Professions Australia. Conducting telehealth consultations via video: a checklist for clinicians. Available: https:// ahpa.com.au/wp-content/uploads/2020/06/Clinician_TelehealthChecklist_FINAL.pdf

51 American College of Physicians. A checklist for incorporation of video visits (telemedicine). Available: www.acponline.org/covid19telehealth-tips
52 NHS England and NHS Improvement. Principles for supporting high quality consultations by video in general practice during COVID-19, 2020. Available: https://www.england.nhs.uk/coronavirus/wpcontent/uploads/sites/52/2020/03/C0479-principles-of-safe-videoconsulting-in-general-practice-updated-29-may.pdf

53 European medicines agency. Guideline for good clinical practice E6(R2), 2016. Available: https://www.ema.europa.eu/en/documents/ scientific-guideline/ich-e-6-r2-guideline-good-clinical-practice-step5_en.pdf

54 NHS England. Using online consultations in primary care implementation toolkit, 2020. Available: https://www.england.nhs.uk/ wp-content/uploads/2020/01/online-consultations-implementationtoolkit-v1.1-updated.pdf

55 The Royal Australasian College of Physicians (RACP). Telehealth: guidelines and practical tips, 2012. Available: https://www.racp.edu. au/docs/default-source/advocacy-library/telehealth-guidelines-andpractical-tips.pdf

56 Smith M, Saunders R, Stuckhardt L. Best care at lower cost: the path to continuously learning health care in America. In: Committee on the learning health care system in America. Washington (DC: National Academies Press (US), 2013. 